Prepared for the U.S. Department of Energy

under Contract DE-AC05-76RL01830

\title{
Interim Report on the Optimization and Feasibility Studies for the Neutron Detection without Helium-3 Project
}

JH Ely

October 2011

Pacific Northwest

NATIONAL LABORATORY

Proudly Operated by Battelle Since 1965 



\title{
DISCLAIMER
}

This report was prepared as an account of work sponsored by an agency of the United States Government. Neither the United States Government nor any agency thereof, nor Battelle Memorial Institute, nor any of their employees, makes any warranty, express or implied, or assumes any legal liability or responsibility for the accuracy, completeness, or usefulness of any information, apparatus, product, or process disclosed, or represents that its use would not infringe privately owned rights. Reference herein to any specific commercial product, process, or service by trade name, trademark, manufacturer, or otherwise does not necessarily constitute or imply its endorsement, recommendation, or favoring by the United States Government or any agency thereof, or Battelle Memorial Institute. The views and opinions of authors expressed herein do not necessarily state or reflect those of the United States Government or any agency thereof.

\author{
PACIFIC NORTHWEST NATIONAL LABORATORY \\ operated by \\ BATTELLE \\ for the \\ UNITED STATES DEPARTMENT OF ENERGY \\ under Contract DE-AC05-76RL01830 \\ Printed in the United States of America
Available to DOE and DOE contractors from the
Office of Scientific and Technical Information,
P.O. Box 62, Oak Ridge, TN 37831-0062;
ph: (865) 576-8401
fax: $(865) 576-5728$
email: reports@adonis.osti.gov \\ Available to the public from the National Technical Information Service, \\ U.S. Department of Commerce, 5285 Port Royal Rd., Springfield, VA 22161 \\ ph: (800) 553-6847 \\ fax: $(703) 605-6900$ \\ email: orders@ntis.fedworld.gov \\ online ordering: http://www.ntis.gov/ordering.htm
}




\section{Interim Report on the Optimization and Feasibility Studies for the Neutron Detection without Helium-3 Project}

October 2011

Prepared for

the U.S. Department of Energy

under Contract DE-AC05-76RL01830

Pacific Northwest National Laboratory

Richland, Washington 99352 
PNNL-20952

\section{Executive Summary}

This report details the results of the work accomplished for the 'Neutron Detection without Helium-3' project during the 2011 fiscal year. The primary focus of the project during this year was to develop models using alternatives to helium-3 to investigate the possibilities and optimizations for multiplicity counters in safeguards applications by computer simulations. The multiplicity counter with significant capability, the Epithermal Neutron Multiplicity Counter (ENMC), was used as the baseline requirement for alternative technologies, which, if a suitable alternative can be found, should also satisfy systems with less stringent requirements, including coincidence counters.

The project is in collaboration with Los Alamos National Laboratory (LANL), and the baseline model of the ENMC that had been developed at LANL with helium-3 as the detector material was used as a starting point. The model was modified to support optimization investigations, and verified with the helium-3 base material. The model was then modified to incorporate boron-trifluoride $\left(\mathrm{BF}_{3}\right)$ gas, which can be used as a proportional gas similar to helium-3. The $\mathrm{BF}_{3}$ gas however, cannot be operated at very high pressure, and therefore optimization were performed with lower pressures and involved changing the tube size and number. The simulation of this model is very similar in approach to the model with helium-3 where the simulation ends when the neutron is captured in the boron. The reaction products are easily detected in the proportional gas, and the simulation results of counting the number of reactions matches well with experimental data.

Next, the tubes were replaced with boron-lined proportional tubes, where the neutron capture material is a thin boron lining inside the tube wall, and which use standard proportional counting gas. For this alternative, the simulation needs to extend beyond the neutron capture, and track the reaction products, which must exit the boron-lining into the counting gas. The reaction products do not always end up in the counting gas, depending on the boron-lining thickness and neutron capture depth. Methods to track the reaction products have been recently implemented into MCNPX and were verified by using several different approaches. The tube number and size were also varied for the boron-lined case.

Finally, work has started on a model of an alternative using lithium-6, another material with a high cross-section for thermal neutron capture. The most promising approach is with lithiumfluoride in a zinc sulfide (silver activated) scintillator medium. The neutron is captured in the lithium, and the reaction products trigger scintillation light in the zinc sulfide, which is subsequently detected by photo-multipliers by the use of light guides or fibers.

The simulations were performed with the focus on determining the efficiency, which is critical when detecting 2 or 3 neutrons in coincidence, as well as the die-away time, which is a measure of the time required to capture neutrons in the system. The die away time is related to the coincident time gate needed for the system which drives the accidental coincident rate, the primary background or noise in this type of measurement. The usual figure of merit for coincidence type systems, the efficiency squared divided by the die-away time, was calculated for each variation simulated.

Initial results indicate that it will be very challenging to find a replacement technology for the ENMC that uses helium-3 at high pressure (10 atmospheres of pressure). The figure of merit 
for the ENMC is on the order of 180 (units of $\%{ }^{2} / \mu \mathrm{sec}$ ), whereas the $\mathrm{BF}_{3}$ and boron-lined (best simulation variation to date) are on the order of 25 . Optimization continues, and significant improvements are expected, but may not be possible to meet the capability of the ENMC with boron proportional tube alternatives. Investigations into other configurations with boron, such as parallel plate converter configurations will be conducted and may provide a more optimal approach. The figure of merit for the $\mathrm{BF}_{3}$ and boron-lined is however in-line with coincident counter performance, and therefore alternatives seem possible for coincident counter applications, although with a large number of tubes.

Previous work with the lithium fluoride has indicated it may be a viable replacement for the ENMC, and simulations are underway to investigate that possibility. Another approach is to detect fast neutrons instead of the traditional thermal capture, which has some advantages, but has been limited by the detectors (primarily liquid scintillators) for these applications. However, recent progress in pulse shape discrimination plastics may provide a cost-effective and solid scintillator, and a small effort has been taken to investigate and measure a sample provided by Lawrence Livermore National Laboratory. 


\section{Contents}

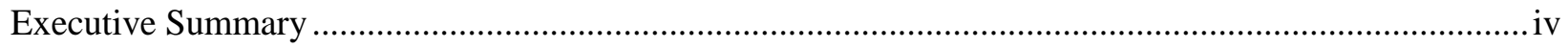

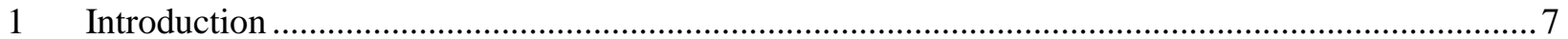

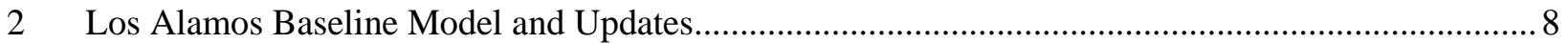

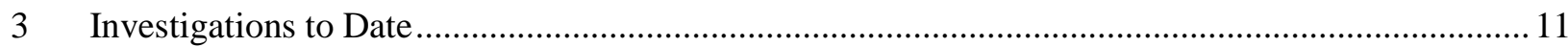

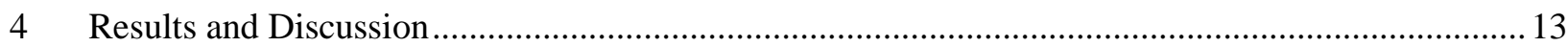

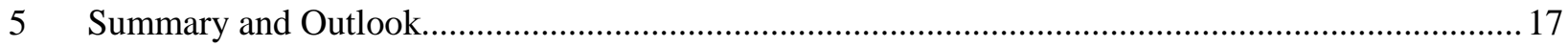


PNNL-20952

\section{Introduction}

This project is focused on investigation an identification of alternatives to helium-3 for neutron detection in multiplicity counters. The project is a collaborative effort with LANL and the initial investigation of the project during this year was to develop models for computer simulations using alternatives to helium-3 for multiplicity counters in safeguards applications. As a baseline capability, the Epithermal Neutron Multiplicity Counter (ENMC125) model, developed by LANL in MCNP was used as the baseline model (and performance) for alternative technologies. The alternatives are focused on boron-10 and lithium- 6 materials, as they are two other materials used for thermal neutron capture. Neither material has the same large cross-section for neutron capture as helium-3, and has other challenges such as detecting the reaction products for the boron-lined case, which limits the overall capability. These shortfalls pose a significant challenge to discover an optimal configuration and approach that will provide the same performance as helium-3. 
PNNL-20952

\section{Los Alamos Baseline Model and Updates}

The MCNPX input code that would establish the baseline of performance for this study was selected by LANL to be the ENMC125 input code. A copy of the ENMC125 input along with an example output was transferred from LANL to PNNL, where it was tested and its detailed construction assimilated. A schematic of the model is shown in Figure 1.

Preliminary changes to the ENMC125 input code were made to provide output (MCTAL files) that would interface with Excel Workbooks for automating (the anticipated numerous) reading, analyzing, and charting of results. Such analysis tools would enable rapid and consistent comparisons of changes made in the search for optimal alternative configurations. These Excel Workbooks (called "MCTALreaders") were developed, tested, put into use for all subsequent evaluations.

Additional modifications to the ENMC125 model were made to provide preliminary $\mathrm{BF}_{3}$ (at one atmosphere of pressure) and boron-lined or BL (with 2.5 um of boron lining) results for the original ENMC125 baseline (121x1" tube) configuration. A variety of "diagnostic" tallies were also used to help determine the flow and spectrum of neutrons throughout the system. Using simplified 1-tube and 1-ring versions of the ENMC125, a preliminary evaluation was also performed to assess the effects of changing the diameter of the tube from 1" to 2" for ${ }^{3} \mathrm{He}(10$ atm and $1 \mathrm{~atm}$ pressure), $\mathrm{BF}_{3}$, and the $\mathrm{BL}$ cases.

From the above experience with the ENMC125 code, and anticipating our needs to continue to alter its construction; a completely re-coded "modular" version of the ENMC125 input file was designed and verified against all previous ENMC125 results (see Figure 2 for top views of this model). The re-coded version was named the Alternative Neutron Multiplicity Counter (ANMC) model, and it has become the template model used in this project (and shared, along with the MCTALreaders, with LANL). The main attribute of the ANMC code is the use of one "master" tube with an automatic generation of all other tubes as clones of the master. The determination of the position of the clones throughout the complete system was also simplified by using a set of standardized input files containing the coordinates of the clones. A separate Excel Workbook (named "XY_TRvalueFinder"-for "XY coordinate TRanslation") was developed to create the clone positions. The $X Y$ TRvalueFinder functions by the user listing as fixed input a specific master tube size and a range of inter-tube spacing, and then working from the inner most ring outwards, the user guides the workbook to find acceptable solutions, i.e. those with an integer number of tubes per ring.

The evaluation procedure of the ANMC code uses a main input file that specifies the details of a master tube, and a set of auxiliary input files that specify the number and position of the cloned tubes. For a new master tube size or shape (e.g. a rectangular, layered plate-type design), the new details of the master are entered in the ANMC main code, and the XY_TRvalueFinder is used to find the acceptable (integer) numbers and positions of the new clones. The numerical results from the $X Y$ _TRvalueFinder are used to create a new set of auxiliary input files, and the new configuration is run using MCNPX. The new output is then processed by the MCTALreaders to produce the reported results. 
PNNL-20952
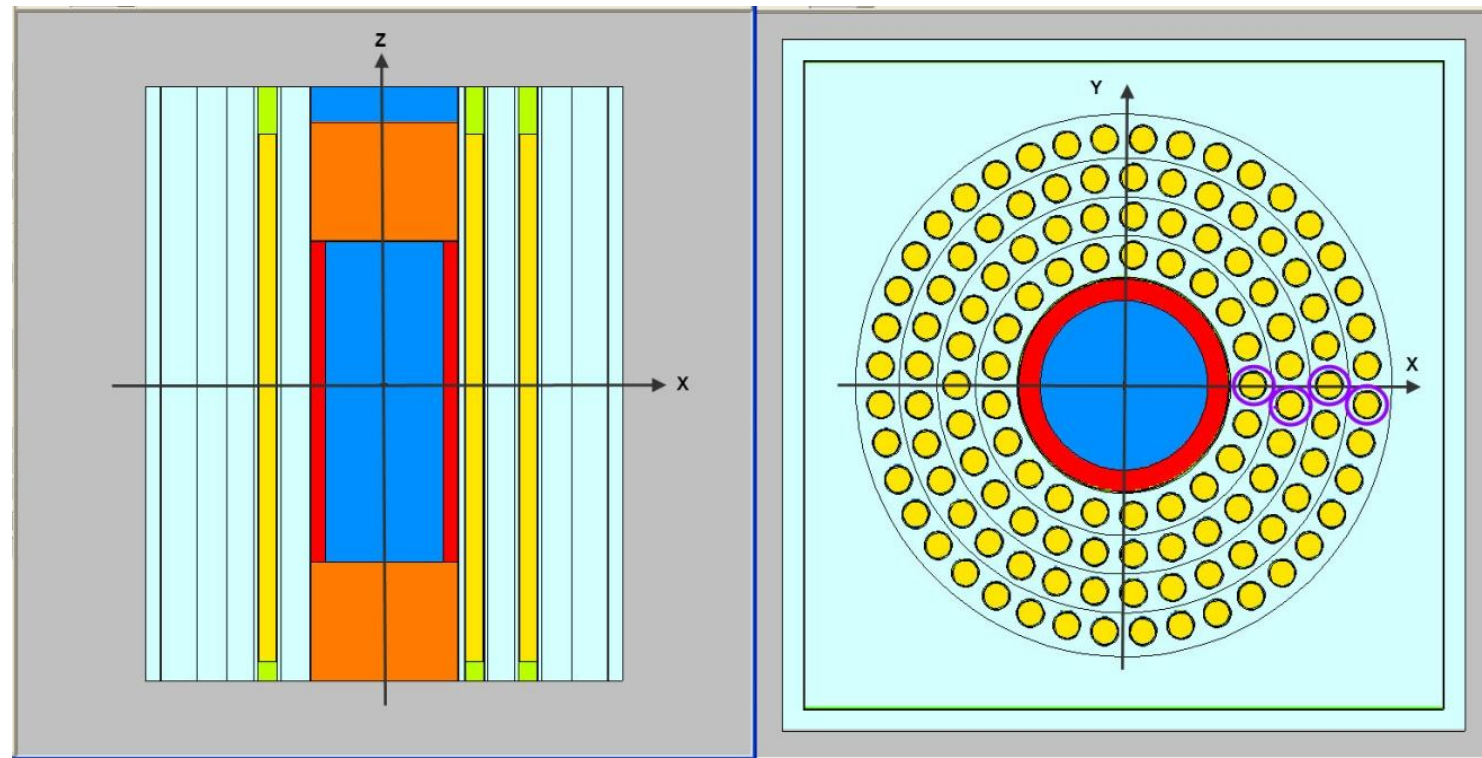

Figure 1. Overview schematic of the ENMC "Baseline" model used in this study. Side view shows sample chamber, 2-cm iron ring (lined with aluminum and cadmium), cadmium-lined graphite end plugs, top air gap, and dead zones in Rings 1, 2, and 3 Tubes (along X-axis). Top view shows rectangular/outer thin cadmium-lined iron shell plus 2.54 inches added polyethylene.

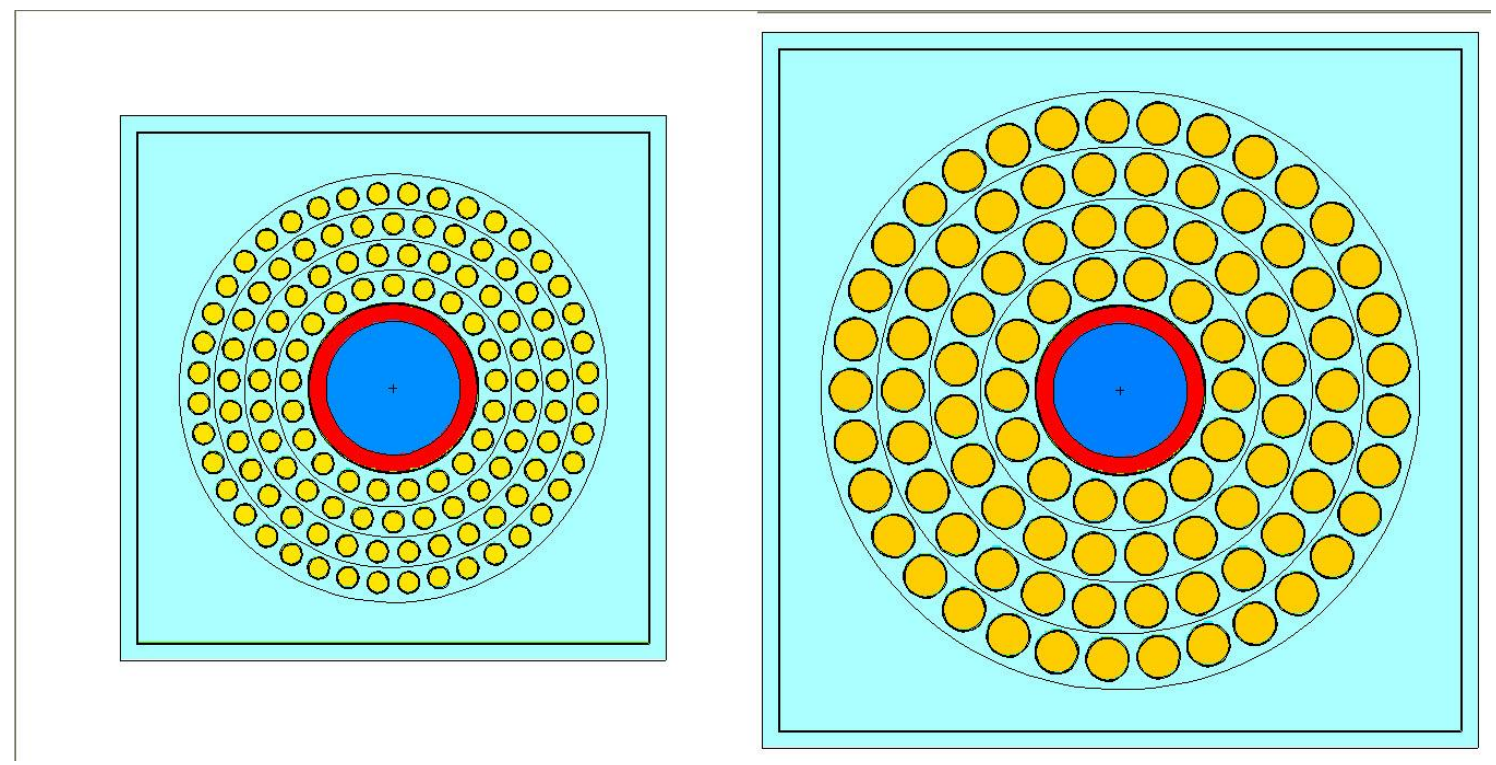

Figure 2. Cross-Sectional (XY) views of the baseline ANMC_1 (left) and the ANMC_2inB (right), a variation using 2-inch diameter tubes.

For the boron-lined model, the reaction products are tracked and the number of reaction products counted that enters into the counting gas of the proportional tube. The tracking is accomplished in MCNPX using a version Beta 2.7b (or newer) with the Neutron Capture Ion Algorithm physics option activated. There are several approaches in MCNPX to estimate the 
number of neutron detected by the reaction products entering the counting gas. First, surface tallies can be collected on the current entering the tube. This provides the energy and number for both the alpha and lithium ions entering the tube, and can be summed to provide the total number, as shown in Figure 3. Since the products are produced with opposite momentum, there is little possibility for double counting. Another approach is to use pulse height tallies, and can be performed using the pulse height light anti-coincidence treatment, or a regular Type 8 tally.

As noted in our INMM2011 conference paper and the ANIMMA 2011 conference paper by M. T. Swinhoe and J. S. Hendricks; a low-energy cutoff (LEC) is needed in the efficiency determination to provide sufficient gamma rejection. However, this effect is on the order of $10 \%$, and so has been neglected for the majority of the parameter studies conducted to date.

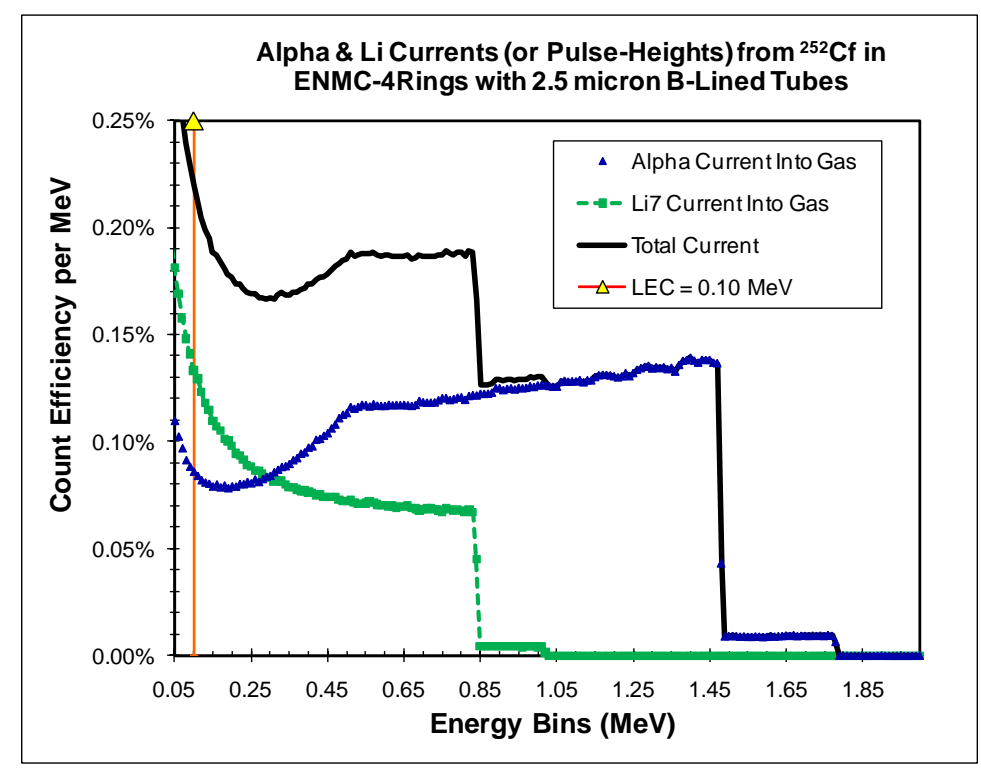

Figure 3. Current tallies for the boron-lined simulations using the baseline ANMC with 121 tubes showing the alpha, lithium, and total currents. Also shown is the effect of setting a low energy cutoff at $100 \mathrm{keV}$. The overall effect is a reduction of $2.6 \%$ for the alpha and $13 \%$ for the lithium currents. 


\section{Investigations to Date}

In order to compare the modeling and simulation results, a figure of merit is needed to evaluate a particular configuration. For this study, the figure of merit that was used in the past to optimize helium-3 based coincidence counters was used. This uses the total efficiency $\boldsymbol{\varepsilon}$ (as a measure of the signal) and the die-away time $\boldsymbol{\tau}$ (as an estimate of the background) along with the "distributions" in $\boldsymbol{\varepsilon}$ as the vertical position, $Z$, and energy, $E$, are varied. These distributions are denoted as $\varepsilon(Z)$ and $\varepsilon(E)$, and are used together with $\varepsilon$ and $\boldsymbol{\tau}$ in to define the Figure-of-Merit (FoM) for comparing the performances of NCC's, FoM $=\left(\varepsilon^{2}\right) /\left(\varepsilon(Z)^{*} \varepsilon(E)^{*} \boldsymbol{T}\right)$. For the relative comparisons made in this study, we set $\varepsilon(Z)=\varepsilon(E)$ $=1$, and the FoM values are evaluated as simply FoM $=\left(\varepsilon^{2}\right) / \boldsymbol{r}$.

For the $\mathrm{BF}_{3}$ technology, several different variations were studied. First the baseline ANMC model was simulated with one atmosphere of $\mathrm{BF}_{3}$ as the proportional counter gas. The one atmosphere of pressure was chosen based on typical $\mathrm{BF}_{3}$ tubes; however, additional investigation on maximizing pressure will be conducted. This indicated the performance was low compared to the helium-3 case at 10 atmospheres of pressure, and therefore, the tube size was increased to two inches. This increased the gas volume by a factor of four. With the larger size tube, the number that could fit into a single ring decreased, resulting in a 93-tube configuration, as was shown in Figure 2. The reduction in the number of tubes decreased the overall volume gain by about $25 \%$. In order to try and gain some additional gas volume (and perhaps reduce the die-away time) the amount of polyethylene between the tubes was reduced, allowing for additional six tubes for a total of 99 tubes (see Figure 4).
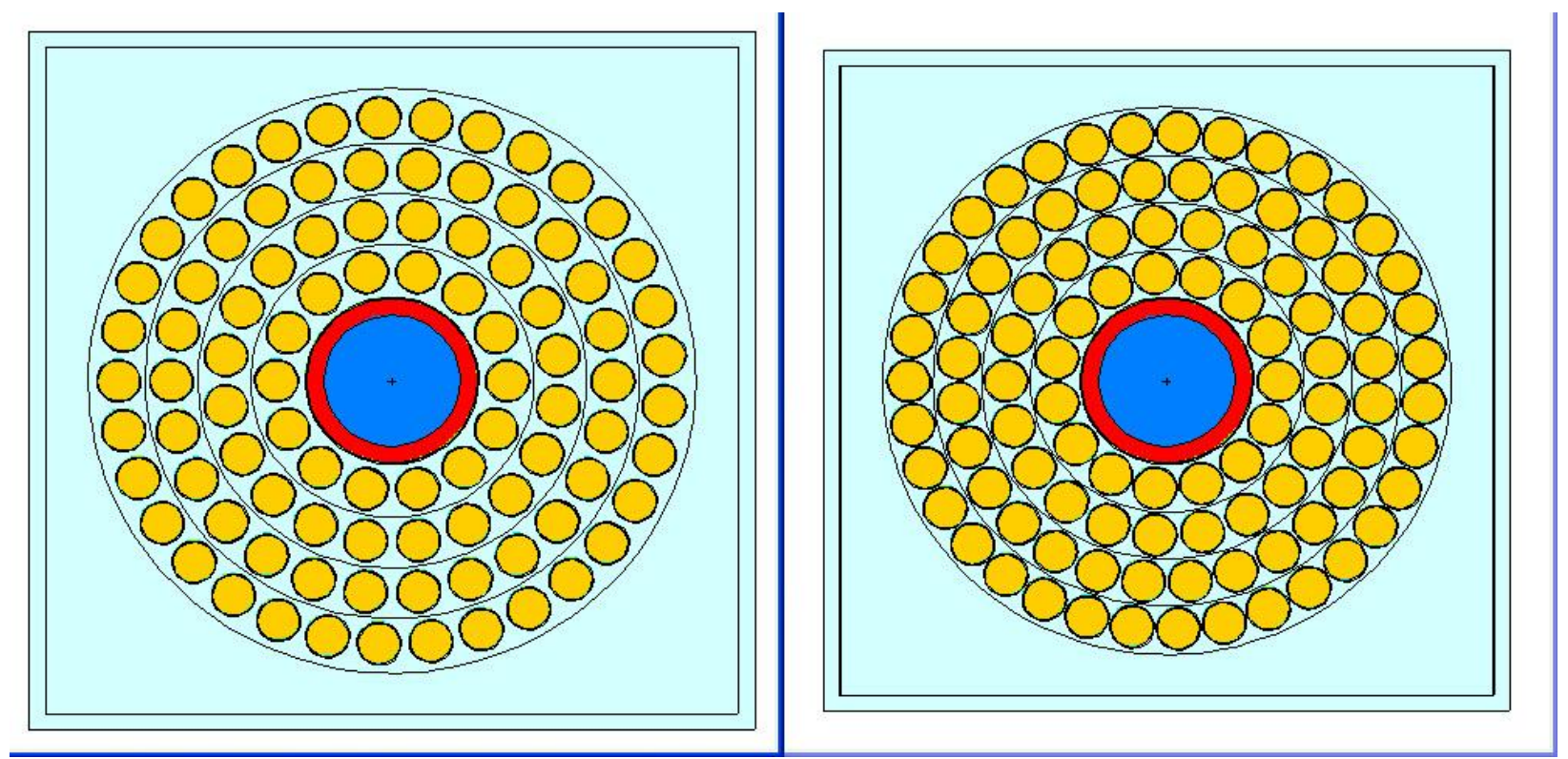

Figure 4. Cross Sectional Views of the 93-Tube "Baseline" 2inB (left) and the 99-Tube "Optimized" 2inAta configuration (right).

The boron-lined tube investigation was approached in a similar fashion as the $\mathrm{BF}_{3}$, that is, the initial configuration was the baseline ANMC, and then variations to increase the efficiency were modeled. First however, a study of the optimal thickness of the boron lining was conducted. The lining was modeled as pure boron, with a $96 \%$ enrichment of boron- 10 . The optimal 
thickness was determined to be 2.5 micrometers (additional detail provide in the next section with the results), and this value was used in subsequent simulations of the boron-lined tubes. The initial 121-tube baseline was modeled, and then 2-inch tubes were investigated. Increasing to a two inch tube diameter increases the area of the lining by a factor of two, and is therefore not as large as an increase as with the volume for the $\mathrm{BF}_{3}$ case. Factoring in the corresponding decrease in the number of tubes, the total increase in efficiency was not significant. Smaller tubes with a larger number provide a better approach, and the first step was to look at smaller tubes within the two-inch diameter configuration. Two different configurations were modeled for this; one with 7 tubes with a 0.5 inch diameter and 19 tubes each with a diameter of $8 \mathrm{~mm}$ (see Figure 5 below). The middle tube contribution was analyzed by performing simulations with the central tube removed, resulting in a 6-tube and 18-tube configuration. For each two-inch tube, a 'cluster' of these small tubes was generated.

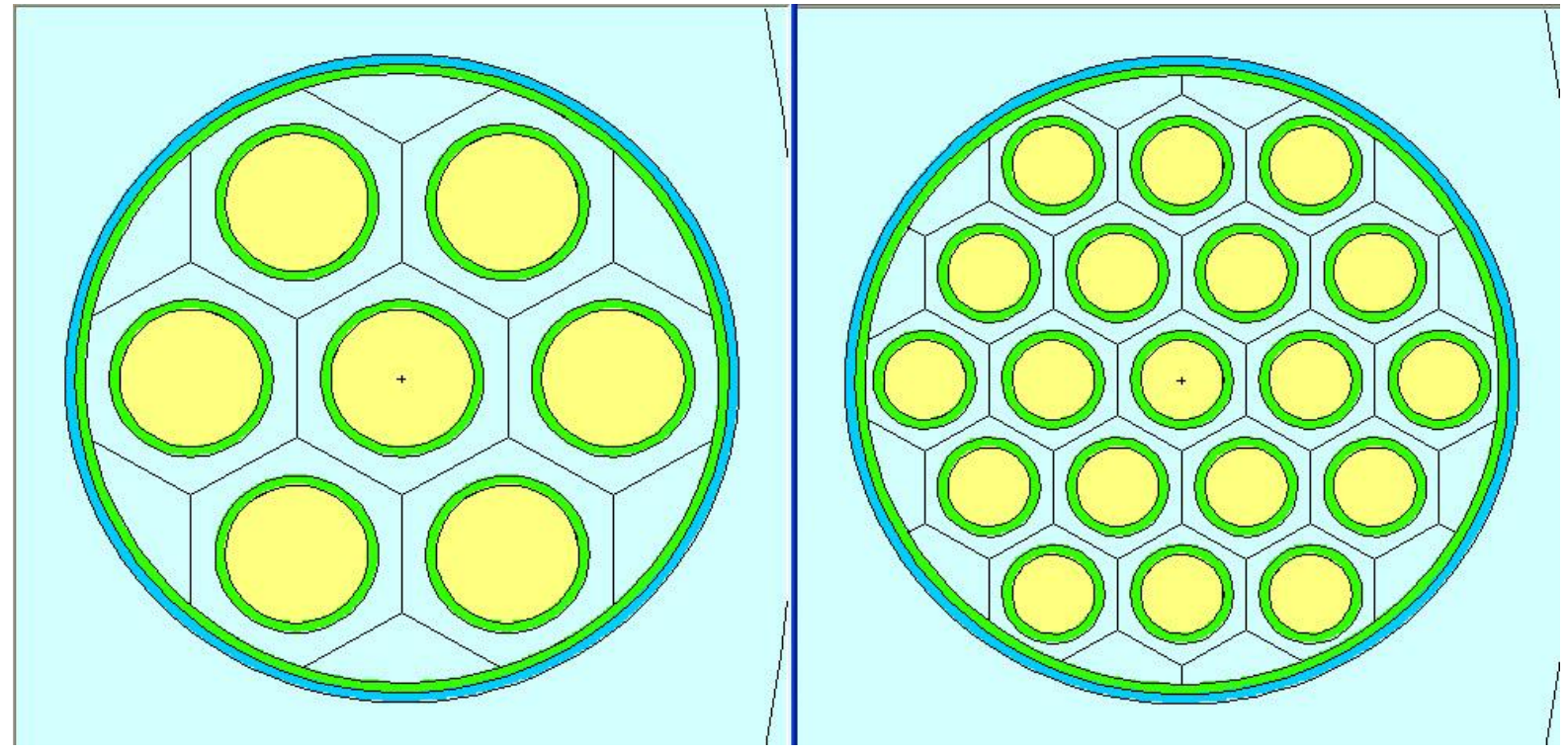

Figure 5. Cross sectional view of the model with small tubes within the 2 -inch diameter tube. Left image shows the seven 0.5 inch tubes, while the right image shows the 19 tubes of $8 \mathrm{~mm}$ diameter. 
PNNL-20952

\section{Results and Discussion}

The optimal boron lining was first modeled to determine the optimal thickness. The $\mathrm{BF}_{3}$ pressure was not optimized at this time, but a one atmosphere pressure was used as this is the typical pressure for large $\mathrm{BF}_{3}$ tube applications. The results of the optimization of the boron lining are shown in Figure 6 for a single tube, which provides the efficiency as function of the thickness, as well as the neutron captures and die-away times. The neutron capture increases as the thickness increases, as more of the neutrons get captured. However, it becomes more challenging for the reaction products to escape the lining into the counting gas, and therefore the efficiency peaks at around 2.5 microns. The die-away time decreases as the thickness increases since slower neutrons get filtered out as they interact near the edge of the lining and the products can't reach the counting gas. The optimal figure of merit (FoM) is when the lining is thicker, peaking at 3 microns, but similar to the 2.5 microns for the optimal efficiency as shown in Table 1 below.

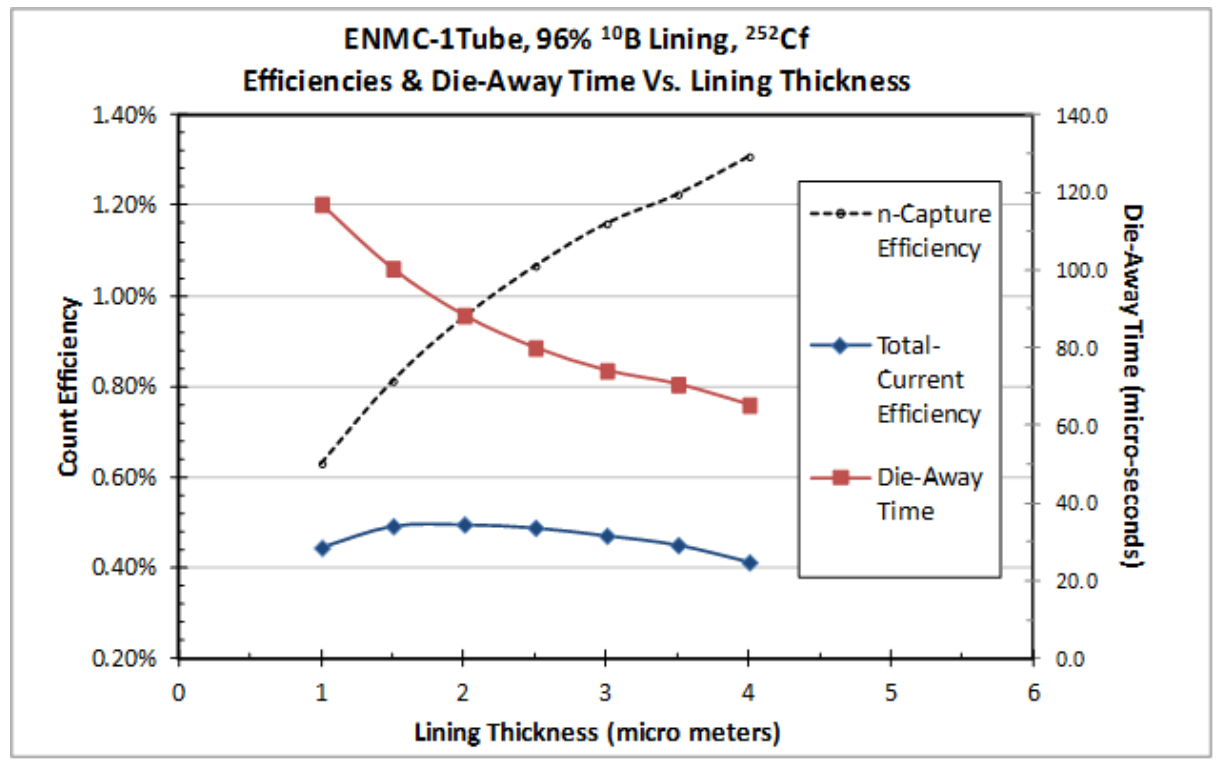

Figure 6. Dependence of neutron capture reactions, surface currents, and die-away times as function of boron lining thickness for a single tube. Although this particular figure shows results for a $2.54 \mathrm{~cm}$ diameter tube, other diameters were also evaluated and a thickness of $\sim 2.5 \mu \mathrm{m}$ appears to maximize the $\varepsilon$ in tubes with outer diameters ranging from $50 \mathrm{~mm}$ to $8 \mathrm{~mm}$.

Table 1. Values for the single boron-lined tube as a function of the thickness.

\begin{tabular}{|c|c|c|c|c|c|}
\hline Thickness $(\mu \mathrm{m})$ & $\begin{array}{r}\text { Detection } \\
\text { efficiency }\end{array}$ & $\begin{array}{r}\text { Die-away time } \\
(\mu \mathrm{s})\end{array}$ & $\begin{array}{r}\text { Neutron capture } \\
\text { efficiency }\end{array}$ & $\begin{array}{r}\text { Detect./neut.- } \\
\text { capture eff. ratio) }\end{array}$ & Figure of Merit \\
\hline 1.00 & $0.45 \%$ & 116.93 & $0.63 \%$ & 0.71 & $1.69 \mathrm{E}-07$ \\
\hline 1.50 & $0.49 \%$ & 100.33 & $0.81 \%$ & 0.61 & $2.42 \mathrm{E}-07$ \\
\hline 2.00 & $0.50 \%$ & 88.32 & $0.95 \%$ & 0.52 & $2.79 \mathrm{E}-07$ \\
\hline 2.50 & $0.49 \%$ & 79.94 & $1.07 \%$ & 0.46 & $2.99 \mathrm{E}-07$ \\
\hline 3.00 & $0.47 \%$ & 74.10 & $1.16 \%$ & 0.41 & $3.00 \mathrm{E}-07$ \\
\hline 3.50 & $0.45 \%$ & 70.57 & $1.22 \%$ & 0.37 & $2.88 \mathrm{E}-07$ \\
\hline 4.00 & $0.41 \%$ & 65.29 & $1.31 \%$ & 0.32 & $2.61 \mathrm{E}-07$ \\
\hline
\end{tabular}


With the optimal boron lining chosen, the results of using the $\mathrm{BF}_{3}$ at one atmosphere and boronlining at 2.5 microns can be calculated for the baseline configuration. Shown in Figure 7 is the time distribution of the neutron detector response, fitted with an exponential function to determine the die-away time. The efficiencies for this baseline ANMC configuration (121 oneinch tubes) are provided in Table 2. The $\mathrm{BF}_{3}$ tubes at one atmosphere provide only $\sim 60 \%$ of the efficiency of the 10 atmospheres of helium-3, and the die-away time is almost 100

microseconds longer. The efficiency of system with the boron-lined tubes is even less that the $\mathrm{BF}_{3}$ tubes, with an efficiency of $\sim 22 \%$, which is about a third of the ${ }^{3} \mathrm{He}$ efficiency. The die-away time is not as long for the boron-lined tubes compared to the $\mathrm{BF}_{3}$, but still on the order of three times longer than for ${ }^{3} \mathrm{He}$.

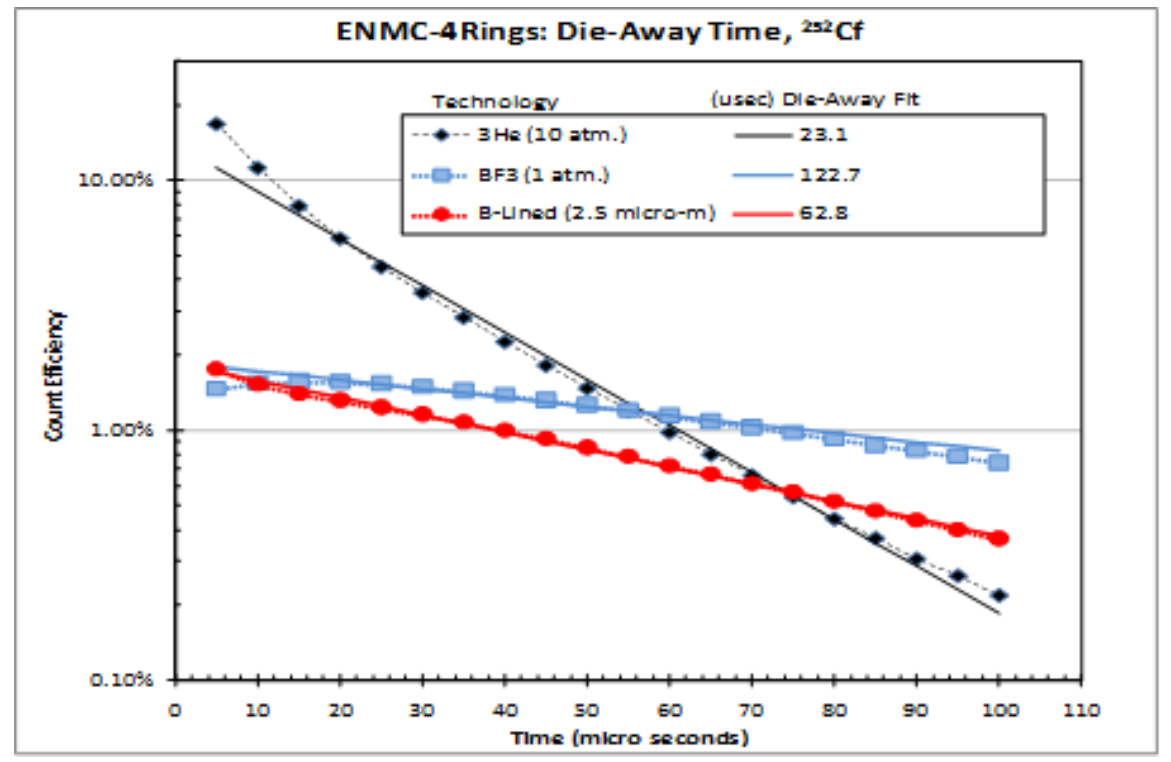

Figure 7. Example of the single-exponential fitting procedure used to determine the die-away times $(\tau)$ in this study. Count efficiencies versus time for in the gas-filled tubes are the F4 tally counts for gas media and sum of alpha and lithium currents (F1 tallies) into the gas for the boron-lined case.

Table 2. Efficiencies calculated from the simulated baseline ANMC model with the three technologies

\begin{tabular}{|l|r|}
\hline Technology & \multicolumn{2}{|c|}{ Total Count } \\
Efficiency
\end{tabular}

After the baseline comparison, the models were modified by increasing the tube size to two inches, with two configurations simulated for each technology. The first configuration maintained the same inner tube amounts of polyethylene, resulting in a 93 tube system. The second configuration decreased the amount of polyethylene between tubes and thereby allowing for more tubes resulting in the 99 tube system. The results are provided in Table 3. Increasing the tube size to two inches increases the volume of the tube by a factor of four, and results in a significant improvement in the efficiency for the $\mathrm{BF}_{3}$ cases nearing $50 \%$, although the total number of tubes has dropped from the baseline of 121. Moving from the baseline polyethylene inner tube thickness results in more tubes, but interestingly enough, less efficiency for the $\mathrm{BF}_{3}$ case. However, the die-away time does drop and the resulting figure of merit is slightly better when the polyethylene is decreased. Although the efficiency has significantly 
increased and getting closer to the ${ }^{3} \mathrm{He}$ value of $65 \%$, the die-away time is quite large and results in a relatively poor figure of merit of $20-25$ for the $\mathrm{BF}_{3}$ case, as compared to 186 for the ${ }^{3} \mathrm{He}$.

The boron-lined simulations indicate that there is basically no increase in increasing the tube size to two inches, although the surface area does increase by a factor of two. The die-away time decreases when the polyethylene is decreased, and the efficiency drops as well, but the overall figure of merit is slightly better when going to the 99 tube case from the 93 tube configuration. The die-away times for the boron-lined case using two-inch tubes increased compared to the one-inch configuration (with a die-away time of 63 microseconds), and the overall figure of merit is poorer. Using a larger tubes size is not the optimal approach for boronlined tubes.

Table 3. Results summary of the simulated two inch tube configurations

\begin{tabular}{|c|c|c|c|c|c|}
\hline Configuration & $\begin{array}{l}\text { Tube } \\
\text { number, size }\end{array}$ & Technology & Efficiency $(\%)$ & $\begin{array}{l}\text { Die-away time } \\
(\mu \mathrm{s})\end{array}$ & Figure of Merit \\
\hline ANMC Baseline & $121,1 "$ & 10 -atm. ${ }^{3} \mathrm{He}$ & 65.6 & 23.2 & 185.7 \\
\hline ANMC-2inB & $93,2 "$ & 1 -atm. $\mathrm{BF}_{3}$ & 49.5 & 114.8 & 21.3 \\
\hline ANMC-2inAta & $99,2^{\prime \prime}$ & 1 -atm. BF & 47.3 & 91.2 & 24.5 \\
\hline ANMC-2inB & $93,2^{\prime \prime}$ & $2.5 \mu \mathrm{m}$ B-Lining & 25.3 & 91.1 & 7.0 \\
\hline ANMC-2inAta & $99,2^{\prime \prime}$ & $2.5 \mu \mathrm{m}$ B-Lining & 24.2 & 75.3 & 7.8 \\
\hline
\end{tabular}

Based on the relatively poor performance of the boron-lined tubes, a model was developed where small tubes were inserted into the two-inch tube configurations, since those models were already developed. Two different size tubes and corresponding numbers were generated; a seven tube model with 0.5 inch diameter tubes (BLL7) and one with $8 \mathrm{~mm}$ tubes (BLL19) with 19 fitting inside the two inch space (shown in Figure 5). For the 93 tube configuration, this resulted in a system with 651 tubes of 0.5 inch diameter, and one with 1767 tubes of $8 \mathrm{~mm}$ diameter, going up to 693 and 1881 tubes when using the 99 two-inch tube configuration. Since the center tube is surrounded by other tubes, a simulation was also performed where the central tube each of these clusters was removed resulting in a six tube cluster (BLL6) and a cluster with 18 tubes (BLL18). The results for the 93 two-inch tube configuration are provided below in Table 4 for the four cases simulated. These configurations do increase the efficiency a couple of percent for the 0.5 inch tubes and about 5 percent for the $8 \mathrm{~mm}$ tubes. In addition, the dieaway time is decreased, and together with the increased efficiency provides increased figure of merit, of the same magnitude as the $\mathrm{BF}_{3}$ two-inch tube configurations. There is little difference in the results when the center tube is removed, indicating that shielding effects are present.

Table 4. Results summary of the small tube clusters in the 93 tube configuration for the boron-lined case

\begin{tabular}{|c|c|c|c|c|}
\hline Configuration & $\begin{array}{l}\text { Tube number, } \\
\text { size }\end{array}$ & Efficiency $(\%)$ & $\begin{array}{l}\text { Die-away time } \\
(\mu \mathrm{s})\end{array}$ & Figure of Merit \\
\hline 2inB with BLL7 & $93 \times 7,0.5^{\prime \prime}$ & 27.7 & 55.1 & 13.9 \\
\hline 2inB with BLL6 & $93 \times 6,0.5 "$ & 26.5 & 59.2 & 11.9 \\
\hline 2inB with BLL19 & $93 \times 19,8 \mathrm{~mm}$ & 30.8 & 42.6 & 22.3 \\
\hline 2inB with BLL18 & $93 \times 18,8 \mathrm{~mm}$ & 30.6 & 43.1 & 21.7 \\
\hline
\end{tabular}

In order to summarize the data in a graphical manner, plots were developed where the efficiency is plotted on one axis and the die-away time on the other. In this representation, constant values of the figure of merit can be overlaid as contours. For this representation, the baseline ${ }^{3} \mathrm{He}$ system was placed, as well as some of the other coincidence counters for 
PNNL-20952

comparison. The baseline ANMC results are shown in Figure 8. Baseline configurations of the ANMC model overlaid with constant figure of merit contours. For comparison the Active Well Coincidence Count (AWCC) and High Level Neutron Coincidence Counter (HLNCC) figures of merit are shown.Figure 8, with additional simulation results provide in Figure 9. The figures of merit are significantly lower than the ${ }^{3} \mathrm{He}$ system but do show improvement as optimization continues. The results are comparable to existing coincidence counters using ${ }^{3} \mathrm{He}$, although the number of tubes is significantly larger than the number in the coincidence systems.

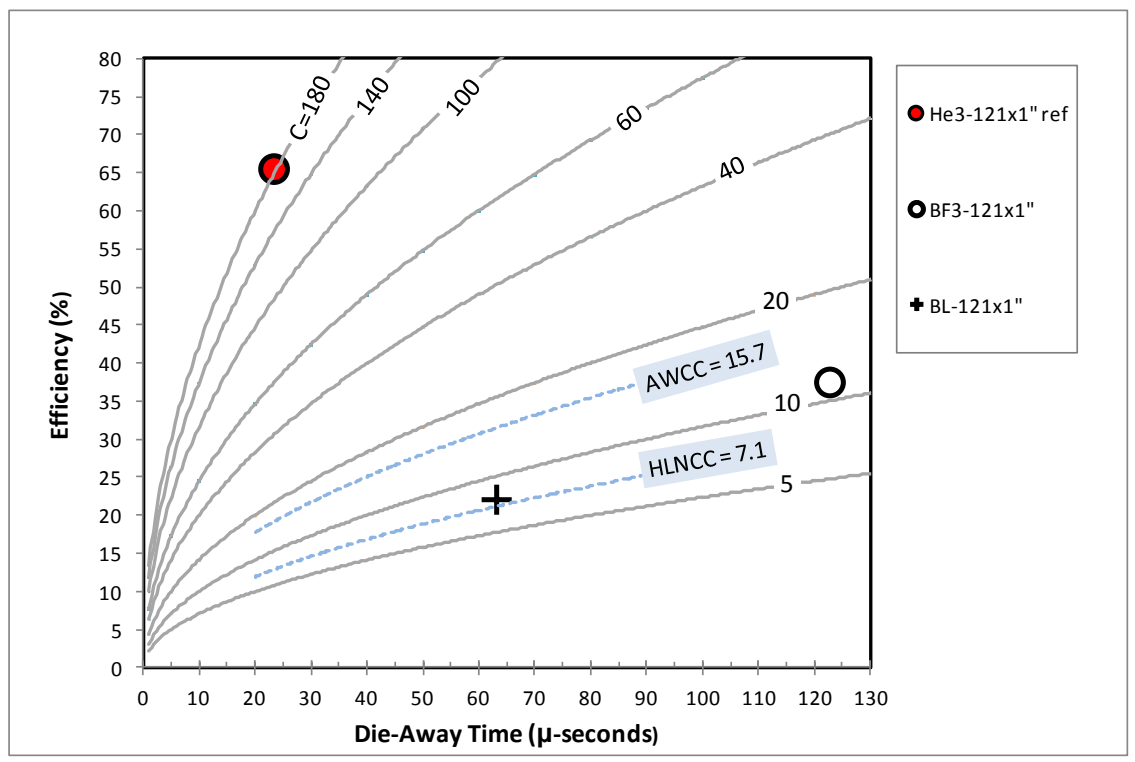

Figure 8. Baseline configurations of the ANMC model overlaid with constant figure of merit contours. For comparison the Active Well Coincidence Count (AWCC) and High Level Neutron Coincidence Counter (HLNCC) figures of merit are shown.

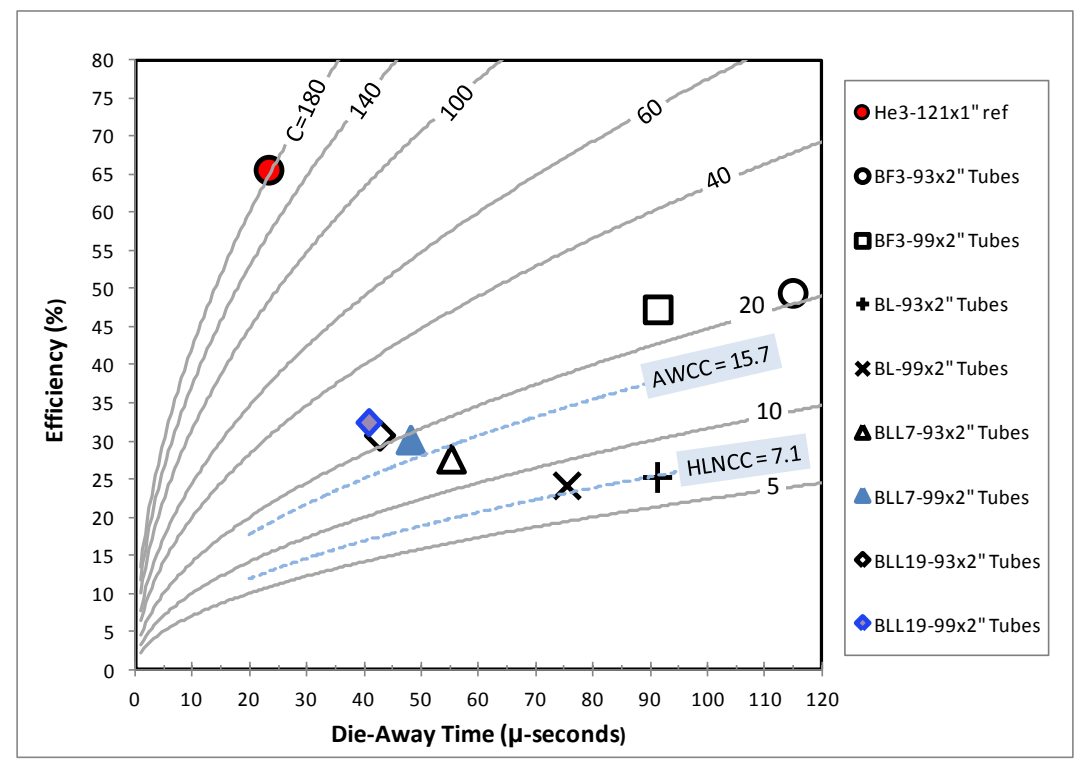

Figure 9. Simulation results overlaid with constant figure of merit contours. Here the 93 and 99 tube configurations are shown for the $\mathrm{BF}_{3}$ and boron-lined cases. For comparison the AWCC and HLNCC figures of merit are shown. 
PNNL-20952

\section{Summary and Outlook}

Models have been developed and simulation performed to investigate alternatives to helium-3 for multiplicity counters. The ENMC model using ${ }^{3} \mathrm{He}$ was used as a baseline for comparison, and models developed and validated against this standard.

A number of configurations were modeled with both the boron-trifluoride and boron-lined proportional tube technologies. Initial results indicate that it will be very challenging to find a replacement technology for the ENMC that uses helium-3 at high pressure (10 atmospheres of pressure). The figure of merit for the ENMC is on the order of 180 (units of $\%{ }^{2} / \mu \mathrm{sec}$ ), whereas the $\mathrm{BF}_{3}$ and boron-lined (best simulation variation to date) are on the order of 25. Optimization continues, and significant improvements are expected, but may not be possible to meet the capability of the ENMC with boron proportional tube alternatives. Investigations into other configurations with boron, such as parallel plate converter configurations will be conducted and may provide a more optimal approach. The figure of merit for the $\mathrm{BF}_{3}$ and boron-lined is however in-line with coincident counter performance, and therefore alternative seem achievable for coincident counter applications, although with a significantly larger number of tubes.

Previous work with the lithium fluoride has indicated that the capability may exist to be a viable replacement for the ENMC, and simulations are underway to investigate that possibility.

Another approach is to detect fast neutrons instead of the traditional thermal capture, which has some advantages, but has been limited by the detectors (primarily liquid scintillators) for these applications. However, recent progress in pulse shape discrimination plastics may provide a cost-effective and solid scintillator, and a small effort has been taken to investigate and measure a sample provided by Lawrence Livermore National Laboratory. 


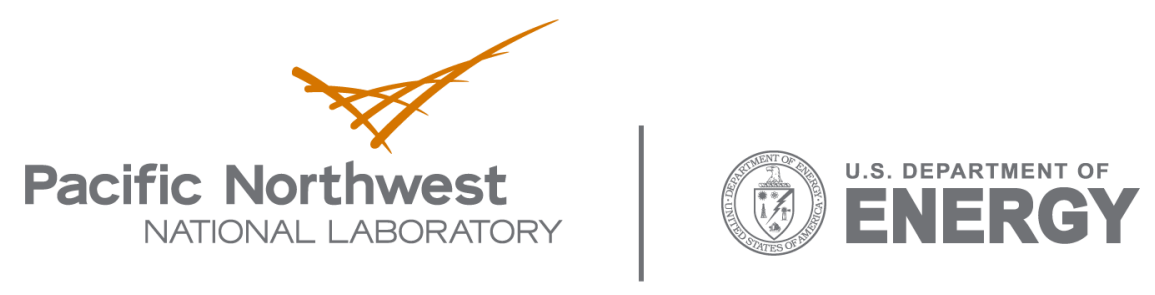

902 Battelle Boulevard

P.O. Box 999

Richland, WA 99352

1-888-375-PNNL (7665)

www.pnl.gov 